Review Article

\title{
Phyllanthus emblica Linn. (Amla) - A Natural Gift to Humans: An Overview
}

\author{
Fairuz Fatema Priya*, Mohammad Sayful Islam \\ Department of Pharmacy, Mawlana Bhashani Science and Technology University, Santosh, Tangail, Bangladesh
}

Email address:

fairuzpriya@gmail.com (F. F. Priya), ronyphar5@gmail.com (M. S. Islam)

${ }^{*}$ Corresponding author

\section{To cite this article:}

Fairuz Fatema Priya, Mohammad Sayful Islam. Phyllanthus emblica Linn. (Amla) - A Natural Gift to Humans: An Overview. Journal of Diseases and Medicinal Plants. Vol. 5, No. 1, 2019, pp. 1-9. doi: 10.11648/j.jdmp.20190501.11

Received: August 16, 2018; Accepted: October 18, 2018; Published: February 15, 2019

\begin{abstract}
Medicinal plants are the precious gift of nature which plays vital role in healthcare system of developing nation and potent source of medicament to heal various diseases in the world. It plays a vital role to preserve our health. Medicinal plants are believed to be much safer. These days, the use of herbal products has become the foremost option for human all over the world because of curing treatment without any side effect. Ayurveda, the oldest health system in the world, provokes the uses amla to treat a host of diseases and promote positive health. It is a well-known fact that all parts of amla are useful in the treatment of various diseases. Among all, the most important part is fruit. Amla fruit is the richest source of vitamin C. Chemical composition of the amla fruit contains more than $80 \%$ of water. It also contains protein, carbohydrates, fiber, amino acids and minerals such as calcium, phosphorus, iron, niacin, carotene, thiamine, riboflavin etc. The chemical constituents present in the plant include tannins, gallic acid, ellagic acid, emblicol, phyllembin, lupeol, essential oil, fixed oil etc. Amla fruit is widely used as diuretic, laxative, liver tonic, antipyretic, hair tonic, ulcer preventive and for common cold, fever as alone or in combination with other plants. Research reports on amla reveals its analgesic, anti-tussive, cardioprotective, cytoprotective, immunomodulatory, chemopreventive, antioxidant, memory enhancing, anticancer, antidiabetic and some others properties. In this article, we review the morphology, distribution, nutritional value, chemical constituents, medicinal uses of amla.
\end{abstract}

Keywords: Phyllanthus emblica, Amla, Medicinal Herb, Nutritional Value, Chemical Constituents, Medicinal Uses

\section{Introduction}

Medicinal plants are the most precious creation of nature which is the ultimate gift for all the creatures includes mankind also. It plays vital role for maintaining the human health. According to WHO survey $80 \%$ of the populations living in the developing countries rely almost exclusively on traditional medicine for their primary health care needs and play an important role in health care system of remaining $20 \%$ of population. Amla (Indian gooseberry) is a gift of nature to mankind. It is an indispensable part of the ayurvedic and unani system with amazing remedial qualities. Phyllanthus emblica fruit is one of the top selling botanicals having diverse applications in healthcare, food and cosmetic industry. According to believe in ancient Indian mythology, it is the first tree to be created in the universe. It is also used in
"TRIPHALA" formulation. Triphala $($ tri $=$ three and phala $=$ fruits), is an ayurvedic preparation composed of three equal proportions of herbal fruits native to the Indian subcontinent. They are: Terminalia chebula, Phyllanthus emblica, and Terminalia belerica. Triphala is rich in polyphenols, vitamin C and flavonoids.

Triphala is known to cure cataract and effective in the treatment of Acquired immune deficiency syndrome (AIDS). There is growing evidence that the humble amla berry offers nearly legendary powers in healing and preventing atherosclerosis and related cardiovascular disease. The amla can make a landscape attractive ornamental tree, especially when it wears its pale green berries. 


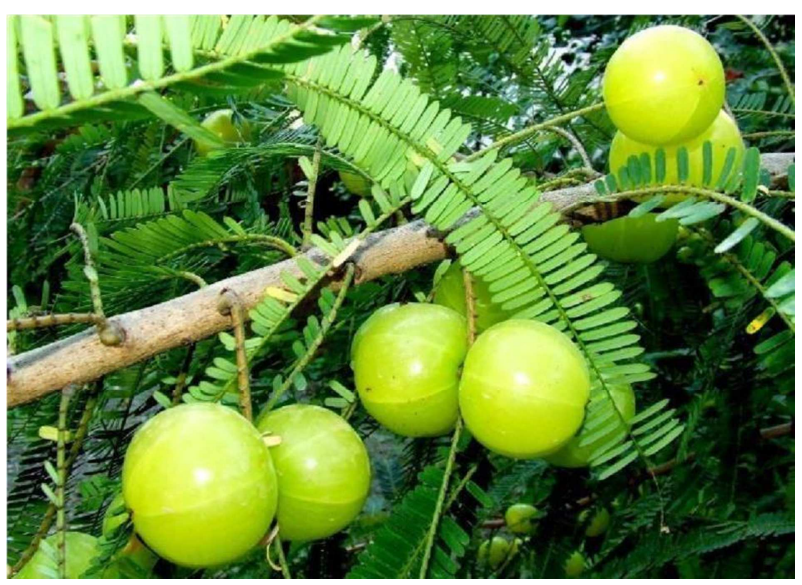

Figure 1. Phyllanthus emblica Linn. (Amla).

\section{Methodology}

This study is a secondary research and secondary data has been used to conduct the study. Secondary data has been collected from different sources like reports of various organization, various books, journals, newspaper and articles. Also vast data have been collected from various web links. By collecting various information we tried to write a summarized overview about Phyllanthus emblica (Amloki).

\section{Result}

\subsection{Geographical Distribution}

Phyllanthus emblica is widely distributed in most tropical and subtropical countries including India, China, Indonesia, Burma, and on the Malay Peninsula. It is native to tropical southeastern Asia, particularly in central and southern India, Nepal, Pakistan, Bangladesh, Bhutan, Srilanka, and the Mascarene Islands. It is abundant in deciduous forests of Madhya Pradesh. Originally, it was cultivated in Madascar. It additionally grows in Pakistan, Sri Lanka, Uzbekistan, Malaysia, Ceylon, Indonesia, and some other countries over the world. Amla is found throughout the seacoast districts and on hill slopes upto 200 meters and is also cultivated in plains. It is a potential crop which grows in the marginal soils and various kinds degraded lands such as salt affected soils, salines and dry and semi-dry regions. With orchard cultivation, about 200 trees can also be accommodated per acre. $[1,12,13]$

\subsection{Botanical Description of the Plant}

Amla is a small to medium sized fruity tree and 8-18 meters height with thin light grey bark exfoliating in small thin irregular flakes, leaves are simple, subsessile, closely set along the branchlets, light green having the pinnate appearance. The flowers are greenish yellow, unisexual. The fruit is nearly globose, quite smooth, fleshy and hard on appearance with six vertical stripes or furrows. The fruits ripen in autumn. It is sour, bitter and astringent in taste and quite fibrous. [5, 12]

\subsection{Taxonomical Classification}

Table 1. Taxonomical Classification.

\begin{tabular}{ll}
\hline Kingdom & Plantae \\
\hline Division & Magnoliophyta \\
Class & Magnoliopsida \\
Subclass & Rosidae \\
Order & Euphorbiales \\
Family & Euphorbiacea \\
Genus & Phyllanthus L. \\
Species & Phyllanthus Linn. emblica \\
\hline
\end{tabular}

[16]

\subsection{Synonyms}

Cicca emblica (L.) Kurz

Diasperus emblica (L.) Kuntze Dichelactina nodicaulis Hance

Emblica arborea Raf.

Emblica officinalis Gaertn.

Phyllanthus glomeratus Roxb. ex Wall. nom. inval.

Phyllanthus mairei H. Lév.

Phyllanthus mimosifolius Salisb.

Phyllanthus taxifolius D. Don

[4]

\subsection{Nutritional Value}

Table 2. Nutritive value per $100 \mathrm{~g}$ of amla fruit.

\begin{tabular}{ll}
\hline Chemical components & Percentage \\
\hline Fruits: Moisture & $81.2 \%$ \\
Mineral matter & $0.7 \%$ \\
Fat & $0.1 \%$ \\
Fiber & $3.4 \%$ \\
Carbohydrate & $14.1 \%$ \\
Protein & $0.5 \%$ \\
Bulk elements $\mathrm{Mg} / 100 \mathrm{~g}$ & Net weight \\
Calcium & $0.05 \%$ \\
Phosphorus & $0.02 \%$ \\
Iron & $1.2 \mathrm{mg} / 100 \mathrm{~g}$ \\
Vitamin C & $600 \mathrm{mg}$ \\
Nicotinic acid & $0.2 \mathrm{mg} / 100 \mathrm{~g}$ \\
\hline
\end{tabular}

[3]

\subsection{Chemical Constituents}

Table 3. Chemical constituents of Amla.

\begin{tabular}{ll}
\hline Part & Constituent \\
\hline & 3-6-di-o-galloyl-glucose, Alanine (5.4\%), Arginine, Ascorbic acid, Aspartic acid, $\beta$-carotene, Boron, Calcium, Carbohydrates, Chebulagic acid, \\
Fruit & Fiber, Chebulaginic acid, Chebulic acid, Chibulinic acid, Chloride, Chromium \\
& (2.5ppm), Copper (3ppm), Corilagic acid, Corilagin, Cystine, Ellagic acid, \\
& Emblicanins, Emblicol, Ethyl gallate, Flavonoids, Gallic acid, zinc ethylester, Gallic acid, Gallotanins, Gibberellin-a-1, Gibberellin- a-3, \\
\hline
\end{tabular}




\begin{tabular}{ll}
\hline Part & Constituent \\
\hline & Glutamic acid, Glycine, Histidine, Iron, Isoleucine, Kaempferol, Leucine, \\
& Lysine, Magnesium, Manganese, Methionine, Myo-inositol, Myristic acid, \\
& Niacin, Nitrogen, Pectin, Phenylalanine, Phosphorus, Phyllantidine, Proline, \\
& Phyllantine, Phyllemblic acid, Phyllemblin, Phyllemblinic acid, Sulfur, \\
& Proanthocyanidins, Proteins, Putranjivin A, Riboflavin, Trigalloyl glucose, \\
& Selenium, Serine, Silica, Sodium, Starch, Sucrose, Thiamine, Threonine, \\
& Tryptophan, Tyrosine, Valine, Zeatin, Zeatin nucleotide, Gibberellin-a-4, Gibberellina-7, Gibberellin-a-9, Glucogallin, Glucose, Zeatin riboside. \\
Leaf & Amlaic acid, Astrogalin, Ellagic acid, Gallo-tannin, Kaempferol, Kaempferol-3oglucoside, Phyllanthin, Rutin, Tannin. \\
Shoot & Chebulagic acid, $\beta$-sitosterol, Chibulinic acid, Corilagin, Ellagic acid, Gallic acid, Glucogallin, Lupeol. \\
Bark & Leucodelphinidin, Lupeol, $\beta$-sitosterol, Betulin, $\beta$-Humulene, Friedelan-3one and Tannins. \\
Seed & Linoleic acid, Linolenic acid, Myristic acid, Oleic acid, Palmitic acid, Phosphatides, Stearic acid, $\beta$-sitosterol. \\
Root & Ellagic acid, Lupeol and Glycosides. \\
Pericarp & Ellagic acid, Emblicol, Gallic acid and Phyllemblic acid. \\
Fruit & Constitutes 90.97\% of the whole fruit, Ascorbic acid, Albumin, Calcium, Crude cellulose, Gallic acid, Gum, Iron, Magnesium, Mineral matter, \\
Pulp & Pectin, Phosphorus, Potassium, Protein, Reducing sugars, Tannins. \\
Seed oil & Arachidic acid, Behenic acid, $\beta$-sitosterol, Linoleic acid, Linolenic acid, Myristic acid, Oleic acid, Palmitic acid and Stearic acid.
\end{tabular}

$[6-11,13,15,17]$

\subsection{Medicinal Importance}

\subsubsection{Traditional Uses in Ayurveda}

The Amla fruit has these properties using the Ayurvedic classifications:

Rasa (taste): Sour and astringent are the most dominant, but the fruit has five tastes including sweet, bitter, and pungent.

Veerya (nature): Cooling, it uses in treatment of burning sensation in inflammation and fever which are considered to be manifestations of pitta (fire) agitation.

Vipaka (taste developed through digestion): Sweet.

Guna (qualities): Light, dry.

Doshas (effect on humors): Quietens all three doshas: vata, kapha, pitta, and is especially effective for pitta.

Due to its cooling nature, amla is a common ingredient in treatments for a burning sensation anywhere in the body and for many types of inflammation and fever; these are manifestations of pitta (fire) agitation. Amla or Amlaki has been considered the best of the Ayurvedic rejuvenative herbs. It has a natural balance of tastes (sweet, sour, pungent, bitter and astringent) all in one fruit, so, stimulates the brain to rebalance the three main components of all physiological functions, the water, fire, and air elements within the body. [2]

In traditional folk medicine, the fruits exert several beneficial effects include cooling, ophthalmic, carminative, digestive, stomachic, laxative, dyspepsia, rejuvenative, diuretic, antipyretic and tonic. They are also useful in diabetes, cough, asthma, bronchitis, dyspepsia, flatulence, peptic ulcer, skin diseases, leprosy, inflammations, diarrhoea, haemorrhages, cardiac disorders, hair tonic and some other disease conditions.

\subsubsection{Acts as an Antioxidant, a Potent Source of Vitamin C and Used To Prevent Scurvy and Jaundice}

The Amla is a rich source of vitamin $\mathrm{C}$ and low molecular weight hydrolysable tannins. For this amla is a good source of antioxidant. The Vitamin $\mathrm{C}$ is bonded with tannins that protect it from being destroyed by heat or light.

The research studies shown that amla preparations contained high levels of the free-radical scavenger, superoxide dimutase (SOD) in the experimental subjects. Amla reduced
UV-induced erythema and showed free-radical quenching ability, chelating ability to iron and copper as well as MMP-1 and MMP3 inhibitory activity.

Ellagic acid, as a powerful antioxidant present in amla has the ability to inhibit mutations in genes and repairs the chromosomal abnormalities. [20-24]

Amla or Indian gooseberry is one of the best remedy for scurvy as it is an extremely rich source of vitamin C.

Oral administration of powder of the dry herb, mixed with an equal quantity of sugar, 3 times a day with milk can prevent scurvy.

Drinking amla juice early in the morning with an empty stomach is a natural tonic prevent outbreak of scurvy and jaundice. [24]

\subsubsection{Memory Enhancing and Antidepressant Activity}

Amla-Berry is good for the brain. It is supportive for the mind and enhance coordination. It sharpen the intellect and helps in mental functioning. It supports the nervous system and strengthens the senses.

$P$. emblica is traditionally used to treat disorders of the central nervous system (CNS). Powder of amla produced a dose-dependent improvement in memory of young and aged rats. It reversed the amnesia induced by scopolamine and diazepam. Powder of amla may prove to be a useful remedy for the management of Alzheimer's disease due to its beneficial effects on memory improvement and reversal of memory deficits.

A test on Albino mice confirmed the antidepressant action of amla as comparable to usual antidepressant drugs. [24, 31, 43]

\subsubsection{Cardioprotective Activity, Hepatoprotective Activity, Anti-inflammatory, Antipyretic and Analgesic Effects, Hypo-cholesterolemic and Hypo-lipidemic Properties}

It supports the heart, blood and circulation. It protects the cardiovascular system and sometimes acts as cardiac stimulant. Research shows that, Amla helps to lower cholesterol level and protect heart from diseases. Various studies shown that, Ischaemia-reperfusion injury (IRI), occur due to oxidative stress can be treated with amla fruit as fruit 
extract enriched with emblicanin A and B. Oral administration of a $P$. emblica fruit extract enriched with emblicanin A and $\mathrm{B}$ (50 $\mathrm{mg}$ and $100 \mathrm{mg} \mathrm{kg}-1 \mathrm{BW}$ twice per day for 14 days) significantly reversed the effects of IRI. [24, 31]

Amla fruits have been reported to be used for hepatoprotection in Ayurveda.

The amla extract was found to be hepatoprotective, due to its membrane stabilising, antioxidant and CYP 2E1 inhibitory properties. Treatment of rats with amla extract $(75 \mathrm{mg} \mathrm{kg}-1$ per day) also enhanced liver cell recovery by bringing the levels of AST, ALT and IL-1 $\beta$ back to normal. Amla-fruit helps to purify the nutrient fluid and blood, thus support the functions of the liver. It also strengthens the liver, helps in the removal of toxins from the body. A hydroalcoholic (50\%) extract of $P$. emblica (fruit) reduced the severity of hepatic fibrosis induced by carbon tetrachloride and thioacetamide. [38]

Extracts of leaves and fruits possess potent anti-inflammatory, antipyretic as well as analgesic activity. This may be due to the presence of tannins, alkaloids, phenolic compounds, amino acids and carbohydrates. Decoction of $P$. emblica leaves is used to treat fever and the fresh fruit is refrigerant. The seeds are given internally as a cooling remedy in bilious affections, nausea and in fevers.

Another research reported that, fruit extract was found to be an effective anticoagulant and anti-inflammatory agent as it potentially and significantly reduced lipopolysaccharide (LPS) induced tissue factor expression and it also decreased the concentrations of pro-inflammatory cytokines, TNF.

Often after a fever there is a loss of taste and a decoction of the emblic seed, dried grapes and sugar is used for gargling.

A paste of the fruit act as analgesic in case of cephalalgia (headache). [33, 36, 40]

Treatment with $P$. emblica fruit for 28 days in hyper-cholesterolemic patients, showed decreases in total serum cholesterol levels. P. emblica extract was shown to inhibit cholesteremia at a higher level than the anti-cholesterol drug Probucol.

Another study shown that, rats fed extract along with a high cholesterol diet for 20 days showed significantly reduced the levels of total, free and low-density lipoprotein (LDL) cholesterol compared to that of diet fed group. An oxidized LDL (ox-LDL) level in the animal blood serum was also reduced. The results suggesting that $P$. emblica may be effective for hypercholesterolemia and prevention of atherosclerosis.

In other study it was found that, P. emblica also reduces serum, aortic and hepatic cholesterol in rabbits. [42]

The lipid-lowering activity of $P$. emblica fruits evaluated in rabbits which fed a high cholesterol diet. The fresh juice of fruits at a dose of $5 \mathrm{~mL} /(\mathrm{kg} \bullet$ day $)$ for 60 days lowered serum cholesterol, triglycerides, phospholipids and LDL levels. [42]

\subsubsection{Antimicrobial, Antimutagenic and Anticancer Activity, Immunomodulatory and Antiproliferative Effects and Cause Apoptosis (Programmed Cell Death)}

Various research studies shown that, Amla fruit, leaf and bark has antimicrobial activity which includes antibacterial, antifungal and antiviral properties. In the antimicrobial study, it was observed that, the extract of Phyllanthus emblica showed high activity against all gram- positive, gramnegative and resistant- bacteria. Especially showed highest activity against Bacillus subtilis, and the zone of inhibition was $25 \mathrm{~mm}$. It showed lowest activity against Salmonella paratyphi, Sarcina lutea, Pseudonomous spp., Salmonella typhi and the zone of inhibition was $8 \mathrm{~mm}$. Antifungal property of amla for Aspergillus is reported. Fruit ethanol and acetone extracts confirmed average pastime toward Fusarium equiseti and Candida albicans where griseofulvin was once used as ordinary antibiotic.

Antiviral activity aslo reported. Pentagalloylglucose can inhibit influenza, a virulent disease. [43]

Amla is a wonder fruit known for the treatment and prevention of Cancer. The potential anticancer effects of aqueous fruit extract of $P$. emblica was tested in several different human cancer cell lines such as A549 (lung), HepG2 (liver), HeLa (cervical), MDA-MB-231 (breast), SKOV3 (ovarian) and SW620 (Colorectal). It inhibits the growth and spread of different types of cancer cell lines at doses of 50-100 $\mu \mathrm{g} / \mathrm{ml}$. It also reduces the side effect induced by radiotherapy and chemotherapy, which generally used for the treatment of cancer.

Cyclophosphamide (CP) is one of the most commonly used alkylating anticancer drugs, but has toxic side effects including immunotoxicity, hematotoxicity and mutagenicity.

It is found that oral administration of an extract of $P$. emblica to rats at a dose of $100 \mathrm{mg} \mathrm{kg}-1$ body weight (BW) per day for 10 days resulted in the modulation of immunological parameters and antioxidants in the kidney and liver in normal as well as cyclophosphamide (50 mg kg-1)-treated animals. The result suggested that, amla extract is very effective in reducing the cyclophosphamide induced suppression of humoral immunity. [24, 29, 36]

Immune system acts as great barrier against any type of infection in our body and immune activation is an effective as well as protective approach against emerging infectious diseases. Amla modulate the immune system and the inflammatory response. Immunomodulatory properties of fruit extracts of $P$. emblica were evaluated using chromium (VI) as an immunosuppressive agent induced arthritic (AIA) rats, indicating that these drugs may provide an alternative approach for the treatment of the arthritis. [37]

The antiproliferative activity of phenolic compounds obtained from $P$. emblica was determined by a 3 (4, 5 dimethylthiazol-2-yl)-2, 5-diphenyl tetrazolium bromide (MMT) assay, using three tumor cell lines, MK-1, HeLa, and B16F10 cells. All the phenolic compounds showed strong inhibition against B16F10 cell growth at a concentration of less than $68 \mathrm{mg} / \mathrm{mL}$ compared to HeLa and MK1 cell growth. The results suggested that, such compounds must be taken in consideration for developing potential cancer chemopreventive agent. [14]

Apoptosis (programmed cell death) is a useful marker for predicting tumour response after anticancer treatment. $P$. 
emblica extract was found to inhibit cell cycle regulating enzymes cdc 25 phosphatase in a does dependent manner. [39]

\subsubsection{Antidiabetic Effect, Diuretic and Supports the Urinary System}

The anti-diabetic activities of amla due to its high vitamin $\mathrm{C}$ content that is effective in controlling diabetes. One tablespoon of its juice mixed with bitter gourd juice, taken daily for two months will stimulate the pancreas and enable it to secrete insulin, thus reducing the blood sugar level. Diet restrictions should be strictly maintained while taking this medication. It will also prevent eye complication in diabetes.

It also involved in regeneration and rejuvenation of beta cells, thus leading to an increased insulin production and secretion. This mechanism greatly decreases the blood sugar levels. Tannins has the capability to enhance glucose uptake and inhibit adipogenesis to make them potential drugs for the treatment of non-insulin dependent diabetes mellitus. The extract exerted rapid protective effects against lipid peroxidation by scavenging the free radicals. Decoctions of the leaves and seeds are used in the treatment of diabetes. Different studies suggested that, fruits, infusion of seeds and decoctions of the leaves and seeds are also used in the treatment of diabetes mellitus. [17, 24, 28]

The fresh fruit is diuretic. A paste of the fruit alone or in combination with Nelumbium speciosum (the Egyptian Lotus), Saffron [more likely to be Curcuma longa (Indian saffron) than Crocus sativus (saffron)] and rose water is a useful application over the pubic region in irritability of the bladder, in retention of urine. It is used as a febrifuge, as an antiinflammatory and unusually as an anti-diuretic. [24]

Amla-Berry is very supportive to the urinary system and can be helpful if anyone feel a mild burning sensation while urinating. It supports natural diuretic action, but does not force water from the body like diuretic pills. In other words, it helps eliminate waste from the body but does not over-stimulate the urinary system.

The paste made by $20 \mathrm{gms}$ of pulp of dried E.officinalis in 160 gms of water till $40 \mathrm{gms}$ are left.

This was mixed with $20 \mathrm{gms}$ of Gur. Regular use of this portion may cure urinary problem. Having amla powder with radish can break the stones present in urinary bladder and washed it out through urine. The best time to have them is morning or evening. [24, 27, 35]

\subsubsection{Lightens Headache, Promotes Body Weight, Enhances Food Absorption and Used as Appetizer and Has Antisecretory, Cytoprotective and Gastroprotective Properties}

Applying mixtures of amla with buttermilk make temperature reduction and give chillness to head and its paste reduce headache. [35]

It helps in balancing nitrogen levels and increasing protein levels very well, which promotes body weight. $P$. emblica contains minerals including chromium, zinc and copper which helps in maintaining proper functioning of the metabolic activities of the body. [35]

The regular use of Amla-Berry can strengthen digestion, absorption and assimilation of food. People taking it feel that they enjoy the taste of food better than before. It improves assimilation of iron for healthy blood. Pickles made from the green fruits used as appetizer. [24, 36]

It improves digestion but does not heat the body, Amla is ideal for calming mild to moderate hyperacidity and some digestive problems. Amla (ethanolic extract) was investigated for its antisecretory and antiulcer activities using various experimental models in rats. It was then suggested that Amla extract exhibit antisecretory, cytoprotective and gastroprotective properties. [24, 31, 36]

\subsubsection{Amla as an Anti-Anaemic Agent, Enhances Fertility and Remedy for Menstrual Disorders, Effective in Vaginal Irritations and HIV-Reverse Transcriptase ((HIV-RT)) Inhibitory Activity}

Anemia is a condition that develops when blood does not contain healthy red blood cells or haemoglobin. Main function of $\mathrm{RBC}$ is the transportation of oxygen into the tissues and anemia is caused due to decrease in oxygen carrying capacity. Anemia can caused due to various factors such as inadequate absorption or intake of iron, reduced intake of vitamin B12 or folic acid, destruction of red bone marrow, hereditary conditions etc. Amla is a good absorption agent of iron. Vitamin $\mathrm{C}$ or ascorbic acid is highly present in amla, which helps to reduce iron deficiency.

The synergistic effect of Neem leaves (Azadirachta indica) in combination with amla can be very effective to patients suffering from iron deficiency anaemia. [36]

Amla-fruit keeps menstruation regular and healthy. It supports the reproductive systems of both men and women and can help overcome difficulty in conceiving. It enhances the reproductive tissue and nurtures the ovaries and sperm that enhances fertility and the possibility of conception. It is especially supportive for women, strengthens the uterus and protects the reproductive system. White discharge in women is the major problems which can be reduced by taking dried amla seeds mixed with honey.

Amla can also increase the sperm count and it acts as an aphrodisiac. [24, 36]

A mixture of the fruit juice and sugar is used for the relief of burning in the vagina. $[33,36]$

Inhibition of HIV-Reverse Transcriptase (HIV-RT) by amla plant extract fractions was tested on Peripheral Blood Mononuclear Cells. The study concluded that, aqueous fraction and $\mathrm{n}$-hexane fraction have highest inhibition of recombinant HIV-RT (91\% and 89\%, respectively) at $1 \mathrm{mg} / \mathrm{ml}$ concentration. Chloroform fraction showed highest inhibition of HIV-RT at $0.5 \mathrm{mg} / \mathrm{ml}$ and carbon tetrachloride fraction at $0.12 \mathrm{mg} / \mathrm{ml}$ concentration. At $0.12 \mathrm{mg} / \mathrm{ml}$ and 0.5 concentrations $50 \%$ of the HIV-RT activity is inhibited in n-hexane fraction and carbon tetrachloride fraction respectively. [41]

\subsubsection{Hair Tonic and Eye Tonic}

Amla-Berry boosts absorption of calcium, thus creating healthier bones, teeth, nails and hair. It also helps maintain vernal hair color and retards premature graying, and supports 
the strength of the hair follicles, so there is less thinning of hair with age.

Dried fruit boiled in coconut oil till solid matter becomes charres, prevents greying. The water in which dried amla pieces are soaked overnight is also nourishing to hair. [24, 34, 35]

The juice of fresh amla has been found to improve eyesight and may be helpful in treating conjunctivitis and glaucoma. A cup ful of amla juice mixed with honey should be taken twice daily for eye problems. Even if one does not suffer from eye disease, amla is also used to reduce intraocular tension and weakness of the eyes.

In another treatment an infusion of the seeds is also used as a collyrium and applied in the inflammations of the conjunctiva and other eye complaints. The exudate collected from incisions made on the fruit is applied externally on inflammation of the eye.

Ophthacare is a herbal eye drop preparation containing basic principles of different herbs in patients suffering from different ophthalmic disorders such as conjunctival xerosis, conjunctivitis, acute dacryocystitis etc. In most cases improvement observed with the treatment of the herbal eye drop. During the course of study no side effects were observed and the eye drop was well tolerated by the patients. Ophthacare exhibit beneficial role in a number of inflammatory, infective and degenerative ophthalmic disorders. [26, 31]

\subsubsection{Miscellaneous}

\section{(i) In Osteoporosis and Dental Problems}

Osteoclasts (OCs) are involved in rheumatoid arthritis and in numerous pathologies associated with bone loss. Current results support the concept that, certain medicinal plants as well as derived natural products from them are of great interest for developing therapeutic approaches against bone disorders, including rheumatoid arthritis and osteoporosis.

A study reported that, extracts of amla fruits exhibit probable activity for the treatment of rheumatoid arthritis and osteoporosis by triggering programmed cell death of human primary osteoclasts. Furthermore, there is a need for effective nutraceuticals for osteoarthritis care. [45]

The roots of Phyllanthus emblica Linn. (10 g) are ground and taken twice daily for one day only after taking food.

Alternatively, the leaves of Phyllanthus emblica Linn. are squeezed to extract the juice. This juice then put in the ear (a few drops) to relief from toothache.

A final alternative is to grind the node of a Phyllanthus emblica Linn. and mix it with water. After vigorous stirring it is filtered through a cloth. This water is put drop by drop in the right ear if the teeth on the left hand side are in pain and vice versa. The remedy is continuing for three days. A cytokine like substances, Zeatin is also present in amla leaves and fruits that helps in refining the mouth, strengthens teeth and bones. [26]

(ii) Snake Venom Neutralizer, Mosquitocidal and Larvicidal Activity

Studies shown that, Phyllanthus emblica possess anti-venom activity both in vivo and in vitro studies. The plant extracts which neutralized the defibrinogenating and inflammatory activity of Vipera russellii snake venom. $V$. russellii venom-caused hemorrhage, coagulant and inflammatory undertaking was greatly neutralized via each plant extracts. No precipitating bands were formed between the snake venom and plant extract which confirmed that the plant extracts possess potent snake venom neutralizing capacity and need further investigation. [31]

In a mosquitocidal property evaluation test observed the larvicidal and pupicidal activities of methanol extract of amla against the malarial vector, Anopheles stephensi showing 98\% mortality rate at $100 \mathrm{ppm}$. The methanol and ethanol extracts of amla also exerted $100 \%$ mortality (no hatchability) at 400 ppm and above.

Another study shown the larvicidal activity of amla ethyl acetate leaf extracts.

The study concluded that the ethyl acetate extract of $P$. emblica exhibited the maximum larvicidal activity (99.6\%) with LC50 (lethal Concentration brings out 50\% mortality) value of $78.89 \mathrm{ppm}$ against the larvae of Aedes aegypti. [36]

\section{(iii) Used in Respiratory Diseases and Reduces Harmful Effects of Cigarette Smoke}

$P$. emblica is the richest natural source of flavonoids and vitamin C. Dietary supplement with amla protects against $K$. pneumoniae mediated respiratory tract infection by keeping a supervision on the induction of pro-inflammatory cytokine like TNF. The expressed juice of the fruit along with other ingredients is used to cure cough, hiccough, asthma and other diseases. [36]

Research suggested that intake of amla juice regularly reduces harmful effects of the cigarette smoke in the lungs. Due to its high anti-oxidant contents, it fights with free radicals liberated from the smoke. [26]

\section{(iv) Improves Muscle Tone and Skin, Revitalizing Effects and Used in Boils and Spots}

Amla-fruit promotes protein synthesis that is why it is good for strengthening muscles and building lean muscle mass. It is an extraordinary Ayurvedic action that offers the athletes and body-builders a natural way to tone muscles and build lean mass. [24]

As amla improves digestion, helps the liver in detoxification and is rich in Vitamin $\mathrm{C}$ and other minerals, it is very good for the skin. It moisturizes the skin, cleanses the tissues of toxins, and supports immunity of the skin against bacterial infection. It helps to enhance glow and luster. Also acts against pimples. Pimples on face caused by impure blood and can be removed by taking amla in combination with neem. $[26,35]$

Amla-Berry increases energy and removes fatigue. It supports regeneration of cells- the process by which old cells are replaced by vital and new ones. Revitalizing effects slow the aging process and maintains strength in old age. Improves body resistance, strengthens heart, hair and glands of body. It also has rejuvenating effect on all organs. It is said that the great ancient sage Muni Chyawan rejuvenated himself in his 
late 70 s and regained his virility by the use of amla. [24, 33]

The pericarp of the fruit is often used as decoctions along with other ingredients and also applied externally on boils with cow ghee to promote suppuration. [24-26].

\section{(v) Heals Wounds and Mouth Ulcers}

Various research suggested that, ascorbic acid and tannins namely emblicanin A and emblicanin B have strong antioxidant action and it is proposed that the addition of these antioxidants support the repair process of cells. [36]

A decoction of the leaves is used as a chemical-free bacteriocidal mouthwash. Bark of the root mixed with honey is applied to inflammations of the mouth and a decoction of the leaves is also useful as a mouth wash in the treatment of aphthae. Another remedy suggests root bark rubbed with honey is used in aphthous stomatitis (an inflammation of the mouth). [26]

\section{(vi) Used in Gonorrhea and Gout, Effective in Both Diarrhea and Constipation}

The juice of the bark combined with honey and turmeric can be used to treat gonorrhea. The Barks notorious to exert anti-diarrheic effects and for treatment of leucorrhoea (vaginal infection). Juice of the bark combined with honey and turmeric is used to cure gonorrhea. [24, 26, 32]

Gout is a form of inflammatory arthritis that develops in some people who have high levels of uric acid and its salts deposited on the blood and joints. This problem is cured by taken of a amla juice with old ghee makes softening of joints and helps in curing gout and also removing the spots caused by measles, chicken pox, small pox. [35]

Fruit decoction is used for the treatment of diarrhea. Mixed with sour milk it can be given in cases of dysentery. A decoction and evaporation of the root solution produces an astringent extract equal to catechu. Infusion of the leaves with fenugreek seed is used during chronic diarrhea. Recent report shows that, the $P$. emblica fruit extract possesses antidiarrheal and spasmolytic activities, by blocking muscarinic receptors and Calcium ion channels. [24, 28, 30]

The fruit sometimes pickled or preserved in sugar. When dry it can be used as laxative, according to some sources the fresh fruit is also laxative and one or two fruits being sufficient for a dose. [26]

\section{(vii) Cures Sleep Disorder, Acts as a Body Coolant and Removes Toxins from Body}

Amla cures sleep disorders like the insomnia. [31]

Amla-Berry is good for all seasons but especially effective in the hot season. In Tibetan medicine, the fruit have been described as having a sour taste with cooling potency. [24, 36]

Individuals who have been eating "junk" food, preservatives and additives have a tend to accumulated and deposited on the liver. In other hand, consumption of alcohol, pain killers, medicines etc regularly increases the buildup of large amount of toxins in our body. Amla-Berry helps the liver in removing chemicals and additives from the body. [24, 31] (viii) Reduces the Risk of Gall Stone Formation, Effective in Piles and Useful as an Anthelmintic Medicine

Amla reduces the risk of gall stone formation in the gall bladder. When there is excess cholesterol in the bile, gall stones are formed. Amla helps in reducing them as it contains vitamin $\mathrm{C}$, which converts the cholesterol into bile acid in the liver. [24]

Piles, also known as haemorrhoids, are swollen veins and muscles around anus or in anal canal. Drinking fresh amla juice with half teaspoon of ghee and 1 teaspoon of honey and $100 \mathrm{Gms}$ of milk after lunch cures chronic piles problem. [35]

In Persia the juice of the fruit is used as a vermifuge and it is generally given with honey; the dose is from 1 to 3 drachms. [14]

\section{(ix) To Stop Nausea, Vomiting and Bleeding of the Nose}

A powder of the amla seed and red sandalwood is given with honey, to stop emesis. [33, 36]

Seed fried in ghee and ground in conjee is applied as Lep to the forehead to stop bleeding from the nose. [33, 36]

\section{(x) In Water Purification}

In certain regions the natives put the young branches into the wells to impart a pleasant flavour to the water, especially if it be impure from the accumulation of vegetable matter or other causes. [35]

\section{Safety Study and Contraindications}

Few phytosterol compounds from $P$. emblica have been reported to have cytotoxic effect in tumor and non-tumor cell lines. Otherwise no reported toxicity has been observed. [19]

Contraindications have not been identified. Information regarding safety and efficacy in pregnancy and lactation is lacking. [14]

\section{Discussion}

From the ancient time to till present, medicinal plants have been playing a key role in the healthcare system of mankind as an extraordinary source of natural medicine. Nowadays the use of herbal products increasing day by day for low or no side effect all over the world. Amla is an important medicinal plant of Ayurveda- an Indian indigenous system of medicine. Due to its strong antioxidant, highest vitamin $\mathrm{C}$ contents and essential biological properties amla used to prevent various innumerable health disorders. It can be used as a possible food additive or in nutraceuticals and pharmaceutical industries. Various extracts and herbal formulations of amla showed activities against various diseases and result is similar to standard drugs. The traditional use of $P$. emblica enforces its effects on almost all of the human ailments, but very few of them have been validated through clinical research. It is the need of hour to explore its medicinal values at molecular level with help of various biotechnological tools and techniques. In future it can act as the diverse subject for the research and development of alternative and complementary medicine. 


\section{Conclusion}

On the basis of its traditional uses on various potential remedies this plant can be used as a natural source for the future drug development. Therefore, our careful consideration must be needed for increasing the use of amla for the treatment of various diseases and its development as a established, potential and safe dosage form.

\section{References}

[1] Brun V, Schumacher T. Traditional Herbal Medicine in Northern Thailand. University of California Press, Berkeley, $1987 ; 349$.

[2] Bajracharya M. B. Ayurvedic Medicinal Plants. Kathmandu; Piyusavarsi Ausadhalaya, 1979.

[3] Gopalan C, Sastri BVR, Balasubramaniam SC. Nutritive value of Indian foods. NIN, Hyderabad, India, 1991.

[4] Available at http://en.wikipedia.org/wiki/Indian_gooseberry.

[5] Xia Q, Xiao P, Wan L \& Kong J (1997). Ethnopharmacology of Phyllanthus emblica L. Chin J Chin Mater Med (Chin); 22: 515-518, 525, 574.

[6] Bhattacharya SK, Bhattacharya A, Sairam K \& Ghosal S (2002). Effect of bioactive tannoid principles of Emblica officinalis on ischemiareperfusion-induced oxidative stress in rat heart, Phytomedicine, 9, 171-174.

[7] Thakur RS, Puri HS \& Akhtar H (1989). Major medicinal plants of India. Lucknow; Central Institute of Medicinal and Aromatic Plants.

[8] Bajpai M, Pande A, Tewari SK \& Prakash D (2005). Phenolic contents and antioxidant activity of some food and medicinal plants, International Journal of Food Sciences and Nutrition, 56 287-291.

[9] Deepak P \& Gopal GV (2014). GC-MS analysis of ethyl acetate extract of Phyllanthus emblica L. bark, British Biomedical Bulletin, 2, 285-292.

[10] Zhang YJ, Liang RJ, Zhao Q, Hong AH, Wang YF \& Cen YZ (2013). Chemical constituents from the fresh leaves of Phyllanthus emblica L. Lishizhen Medicine and Materia Medica Research, 24, 1298-1300.

[11] Habib-ur-Rehman, Yasin KA, Choudhary MZ, Khaliq N, Attaur-Rahman, Choudhary MI \& Malik S (2007). Study on the chemical constituents of Phyllanthus emblica, Natural Product Research, 21, 775- 781 .

[12] Emblica officinalis. Natural Remedies Pvt. Ltd., Quality Control Dept., Hosur Road, Bangalore.

[13] Warrier PK, Nambiar EK, Ramankutty C (1997). Indian Medicinal Plants - A Compendium of 500 Species. Part. 3, p. 256-63.

[14] Potawale S. E.*, Vetal Y. D, Mehta U. K, et al. (2008). Phytoconstituents And Therapeutic Potential Of Phyllanthus Emblica: A Review. Pharmacologyonline 2: 236-255.

[15] Srivasuki K. P. (2012). Nutritional and Health Care Benefits of Amla. Journal of Pharmacognosy, 3 (2), 147-151.
[16] http://plants.usda.gov/java/classificationServlet?source=displa $\mathrm{y} \&$ classid=PHEM 2 .

[17] Sampath Kumar K. P., et. al, (2012). Recent Trends in Potential Traditional Indian Herbs Emblica officinalis and its Medicinal Importance. J of Pharmacognosy and Phytochemistry 1 (1), 18-28.

[18] Anthony C. Emblica officinalis [Syn: Phyllanthus Emblica] or Amla: the Ayurvedic wonder; David Mitchell, Chesham Chemicals Ltd.

[19] Qi WY, Li Y, Hua L, Wang K, Gao K. (2012). Cytotoxicity and structure activity relationships of phytosterol from Phyllanthus emblica. Fitoterapia; 84C: 252-256.

[20] Bhattacharya A., Chatterjee A., Ghosal S. and Bhattacharya S. K. (1999). Antioxidant activity of active tannoid principles of Emblica officinalis. Amla. Indian Journal of Experimental Biology, 37: 676-680. PMid: 1052-2157.

[21] Poltanov EA, Shikov AN, Dorman HJ, Pozharitskaya ON, Makarov VG, Tikhonov VP, et al. Chemical and antioxidant evaluation of Indian gooseberry (Emblica offi cinalis Gaertn., syn. Phyllanthus emblica L.) supplements; Phytother Res 2009; 23: 1309-1315.

[22] Prakash D, Upadhyay G, Gupta C, Pushpangadan P and Singh KK (2012). Antioxidant and free radical scavenging activities of some promising wild edible fruits. Int. Food Res. J. 19 (3): 1109-1116.

[23] Priya G, Parminder N and Jaspreet S (2012). Antimicrobial and antioxidant activity on Emblica officinalis seed extract. Int. J. Res. Ayur. Pharma. 3 (4): 591-596.

[24] Ekta Singh et al, Phytochemistry, traditional uses and cancer chemopreventive activity of Amla (Phyllanthus emblica): The Sustainer. Journal of Applied Pharmaceutical Science 02 (01); 2011: 176-183.

[25] www.hillgreen.com.

[26] Bhide MM., Nitave SA. (2014). Roles of emblica officinalis (amla) in medicine by - World Journal of Pharmacy And Phamaceutical Sciences. Volume: 3, 604-615.

[27] Mirunalini S, Vaithiyanathan V \& Krishnaveni M. (2013). Amla: a novel ayurvedic herb as a functional food for health benefits"'- a mini review; International Journal of Pharmacy and Pharmaceutical Sciences. Vol 5, 0975-1491.

[28] Srivasuki KP. Nutritional And Health Care Benefits Of Amla.

[29] Krishnaveni M. \& Mirunalin S. Amla - The Role of Ayurvedic Therapeutic Herb In Cancer.

[30] Kumar A, Singh A \& Dora J. Essentials Perspectives For Emblica Officinalis.

[31] Khan K. H., Roles of Emblica officinalis in Medicine - A Review, Botany Research.

[32] Anil Kumar et al, International journal of pharmaceutical and chemical sciences, vol 1 (1) Jan - Mar 2012.

[33] Swetha Dasaroju et al (2014). Current Trends in the Research of Emblica officinalis (Amla): A Pharmacological Perspective, Int. J. Pharm. Sci. Rev. Res., 24 (2); 150-159.

[34] Health.sify.com/ Ayurveda-Medicinal Properties Of Amla. 
[35] Vasant BS, Bhaskarrao DA, Bhanudas SR; Emblica Officinalis - The Wonder Of Ayurvedic Medicine; World Journal of Pharmacy And Phamaceutical Sciences, Vol: 3, 285-306.

[36] Charmkar NK and Singh R. Emblica officinalis Gaertn. (Amla): A Wonder Gift of Nature to Humans. International Journal of Current Microbiology and Applied Sciences, Vol- 6, 4267-4280.

[37] Srikumar, R., Parthasarathy, N. J. and Sheela, D. R. (2005). Immunomodulatory activity of triphala on neutrophil functions. Biol. Pharm. Bull., 28 (8): 1398-403.

[38] Tasduq SA, Kaisar P, Gupta DK, et al., Protective effect of a 50\% hydroalcoholic fruit extract of Emblica officinalis against antituberculosis drugs induced liver toxicity. Phytother Res. 2005; 19 (3):193.

[39] Rajeshkumar NV, Radahakrishna Pillai M, Kuttan R. Induction of Apoptosis in Mouse and Human Carcinoma Cell Lines by Emblica officinalis Polyphenols and its Effect on Chemical Carcinogenesis. J Exp Clin Cancer Res 2003; 22: 201-212.

[40] Dang GK, Parekar RR, Kamat SK, Scindia AM, Rege NN. Antiinflammatory activity of Phyllanthus emblica, Plumbago zeylanica and Cyperus rotundus in acute models of inflammation. Phytother Res. 2011; 25 (6):904-908. n Chemical Carcinogenesis. J Exp Clin Cancer Res 2003; 22: 201-212.

[41] Estari M., Venkanna L., Sripriya D. and Lalitha R. (2012). Human Immunodeficiency Virus. HIV1) reverse transcriptase inhibitory activity of Phyllanthus emblica plant extract. Biol. Med., 4 (4): 178-182.

[42] Gaire BP. \& Subedi L. Phytochemistry, Pharmacology and Medicinal Properties of Phyllanthus emblica Linn.

[43] Hasan MR, Islam MN \& Islam MR. Phytochemistry, pharmacological activities and traditional uses of Emblica officinalis: A review; International Current Pharmaceutical Journal.

[44] Jahan N. \& Akter S. (2015). Assessment of the antimicrobial activity of the ethanolic extract of Phyllanthus emblica in combination with different classes of antibiotics against single and multidrug resistant strains; Journal of Pharmacognosy and Phytochemistry; 4 (4): 142155.

[45] Bhandari PR, Kamdod MA. (2012). Emblica officinalis (Amla): $A$ review of potential therapeutic applications; International Journal of G. 